\title{
Density structure inferred from gravity anomalies in the eastern area of the Itoigawa-Shizuoka Tectonic Line, central Japan
}

\author{
Masao Komazawa \\ National Institute of Advanced Industrial Science and Technology, Tsukuba, Ibaraki, Japan
}

(Received June 2, 2004; Revised December 7, 2004; Accepted December 7, 2004)

\begin{abstract}
A gravity survey was conducted between October 2002 and December 2003 in and around the eastern area of the Itoigawa-Shizuoka Tectonic Line (ISTL). The total number of measurement points amounted to about 436 and 326 stations were taken at the same points as the seismic survey points. The location and altitude were decided by differential GPS and the accuracy is thought to be within several ten-centimeters. The data was compiled from existing data (Geological Survey of Japan, 2000), so the total number of compiled gravity maps is about 3,540 points. All measured gravity data were referred to the International Gravity Standardization Net 1971 (IGSN71) and the normal gravity values were estimated according to the gravity formula of 1980 . Terrain corrections were conducted within a range of $60 \mathrm{~km}$ by approximating the real topography to an assemblage of annular prisms interpolated by mesh terrain data and random terrain data of the gravity points. The effect of the sinking of the topography due to the Earth's curvature was taken into consideration. Bouguer corrections within a range of $60 \mathrm{~km}$ in arc distances were made using a spherical cap crust formula. The density for both terrain correction and Bouguer corrections was chosen to be $2,670 \mathrm{~kg} / \mathrm{m}^{3}$, because the mean surface density of the whole area is estimated to be a slightly large density by the CVUR method. The features of Bouguer anomalies is characterized by a low anomaly in Omachi city, in the northern parts of Matsumoto basin, and a high anomaly in the central highlands, Central Uplift Zone, about $10 \mathrm{~km}$ west of Ueda city. The low anomaly shows that the thickness of the sedimentary layer is more than $1 \mathrm{~km}$ from $2 \mathrm{D} / 3 \mathrm{D}$ automatic analysis.
\end{abstract}

Key words: Itoigawa-Shizuoka Tectonic Line, Omine belt, CVUR method, 3-D gravity basement, Central Uplift Zone, fold structure.

\section{Introduction}

A gravity survey was carried out between October 2002 and December 2003 in and around the eastern area of the Itoigawa-Shizuoka Tectonic Line, in the central district of Japan, in order to investigate the underground structure. The main object was to reveal the surface-layer density distribution, the configuration of the high-density basement structure, i.e. gravity basement, and the 2-D multi-layer structure across the ISTL from gravimetric analysis. Since there is no uniqueness in the result obtained from the gravity analysis, referring to the deep subsurface structure acquired from seismic survey and/or geological information, is also required for forward modeling. On the topography, there are depression structures extending north and south, called the Matsumoto basin, and Omachi City is in the northern part of it. At the same time, a seismic reflection/refraction survey was carried out in the autumn of 2002 from Omachi city to Komoro city (Sato et al., 2004). The western part of the seismic survey profile is flat and the thick sedimentary layer is estimated. The central part of this study area is mountainous, and the bedrock outcrops there.
Copy right(c) The Society of Geomagnetism and Earth, Planetary and Space Sciences (SGEPSS); The Seismological Society of Japan; The Volcanological Society of Japan; The Geodetic Society of Japan; The Japanese Society for Planetary Sciences; TERRAPUB.

\section{Gravity Survey in the Eastern Area of the Itoigawa-Shizuoka Tectonic Line}

The gravity meters, LaCoste \& Romberg G-type (G579), Scintrex CG-3M (S/N355) and ZLS Burris (B-001), used in this survey are good calibrated gravity meters used for the nationwide gravity survey of Japan. As for accuracy, the calibration of these gravity meters was done at the Tsukuba Mountain calibration route and it was found that there were no problems with the instrument factor. For the decision of position and altitude, optical measuring, total station, and differential GPS system were adopted. The differential GPS device was made by the Magellan Systems Corporation and is portable. Its weight is only $2 \mathrm{~kg}$. The position and altitude were decided with an accuracy of within several ten-centimeters, several centimeters in good condition, from the base station.

For the gravity measurement, the loop-closing method was used, because the gravimeter with spring has some drift. The gravity base station was established at the same site as the GPS base station.

\section{Data Processing of Measured Gravity Data}

All measured gravity data were referred to the International Gravity Standardization Net 1971 (IGSN71) (for example, see Woollad, 1979) and normal gravity values were calculated according to the Geodetic Reference System 1980 (GRS80). Bouguer corrections were made in a 


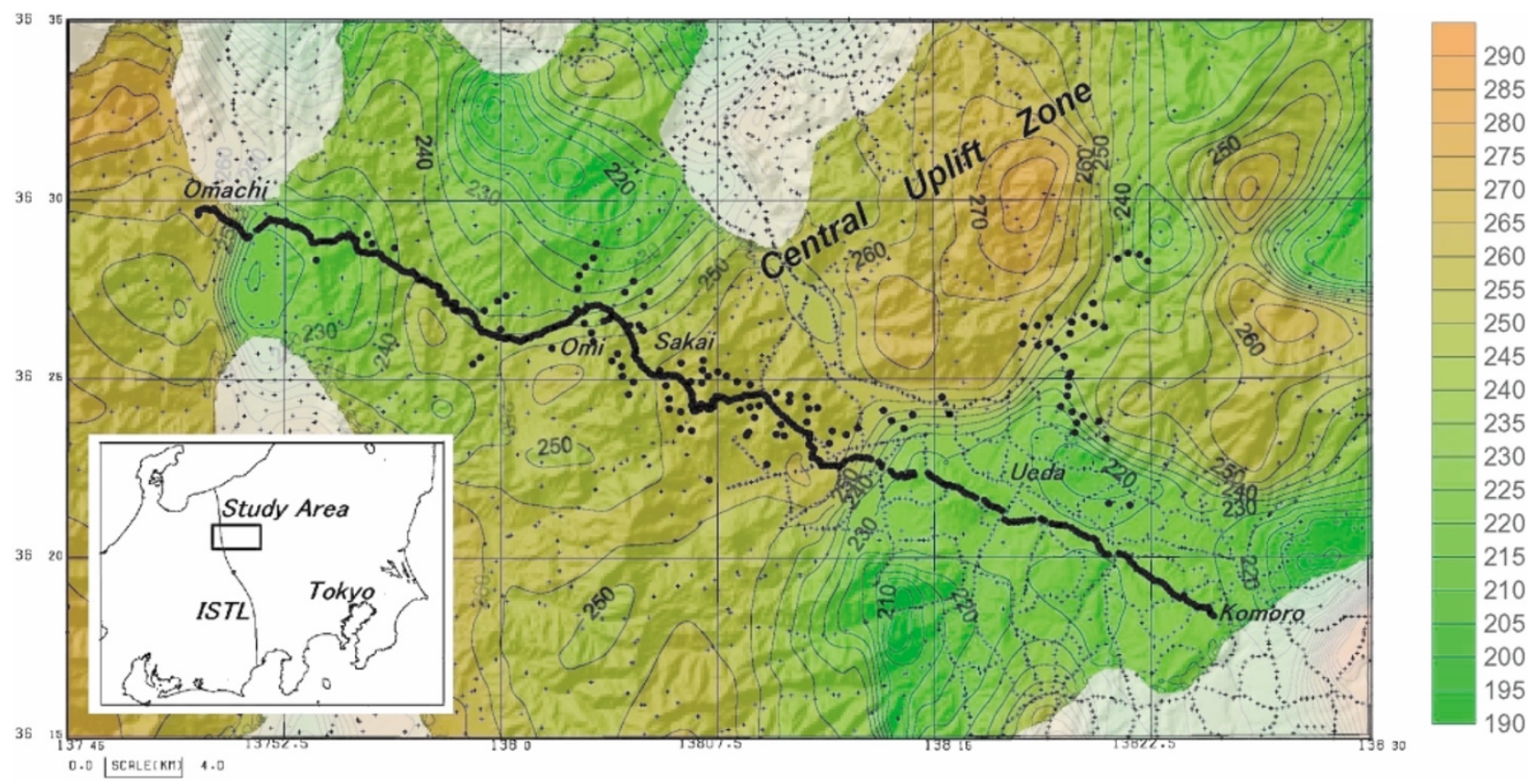

Fig. 1. Two-dimensional distribution of the estimated surface layer densities by the CVUR method. The values of the contour denote the density in $\mathrm{kg} / \mathrm{m}^{3}\left(\mathrm{~g} / \mathrm{cm}^{3}\right)$ multiply by $0.1(100)$. Relief is topographical and made from a $50 \mathrm{~m}$ digital elevation model of the Geographical Survey Institute. Thick circles show gravity stations measured in 2002 and 2003 and thin crosses show the gravity stations measured before 2002.

circular region within a radius of $60 \mathrm{~km}$ in arc distance using a spherical cap crust formula. Terrain corrections were also made for the same region by approximating the real topography to an assemblage of annular prisms derived from the elevation data of DEM (two kinds of digital elevation models: KS-110 (250 m mesh) and $50 \mathrm{~m}$ DEM of the Geographical Survey Institute) and from the gravity stations (Komazawa, 1988). The effect of the Earth's curvature was taken into consideration.

\section{Estimation of the Surface-Layer Density}

In this paper, density distribution of the surface layer is estimated by the method of CVUR (comparison of variance of upward-continuation residual) (Komazawa, 1995). The surface layer is thought to produce the shortest wavelength component of Bouguer anomalies. If the assumed density coincides with that of the surface layer, the first layer behaves like a transparent one, and the short wavelength components caused by the surface topography must attenuate. A convenient way is to compare variances obtained from high-pass or band-pass filtered residuals and to determine the suitable density as the one which gives the minimum variance. The variances are considered to be a measure of randomness or roughness of the skin effects. In this paper, a band-pass filter combined with two upward-continuation filters is used. The grid size must be small enough to pick up detailed information specific to individual measurement points, so here, a grid size of $100 \mathrm{~m}$ is adopted. The results thus obtained are shown in Fig. 1. It is obvious that the greater the undulation of topography, the better the estimation of the surface layer density become, so the result that is not accurate is excluded. The estimated value of low density, 2,200 to $2,300 \mathrm{~kg} / \mathrm{m}^{3}$, around the Omachi basin, Ueda basin and Komoro basin, topographically flat area, is rea- sonable for Quaternary sediments. The central part around Omi and Sakai, Central Uplift Zone (Yano, 1989), is included in the area of high density, 2,500 to $2,600 \mathrm{~kg} / \mathrm{m}^{3}$, and it is reasonable that high density rocks of Middle Miocene sediments, Neogene intrusive rock, and Pliocene andesite outcrop there.

\section{Characteristic of Bouguer Gravity Anomalies}

The survey area is a distribution of a sedimentary layer or basement rocks, so the average surface-layer density is estimated from the result of the CVUR method. The density for both terrain correction and Bouguer correction is taken to be $2,670 \mathrm{~kg} / \mathrm{m}^{3}$. The Bouguer anomaly map of the whole surveyed area is shown in Fig. 2. The feature of the Bouguer anomaly map is similar to the geologic setting (Geological Survey of Japan, 1989; Geological Survey of Japan, 1998), i.e. Quaternary sediments, Miocene sediments, or Neogene intrusive rock. The feature of Bouguer anomalies is characterized by the low anomaly in the western part of the survey area. The low anomalies show that the thickness of the sedimentary layer is very large around Omachi City. The active faults, the Itoigawa-Shizuoka Tectonic Line (ITSL), and Otari-Nakayama Fault are also clear and it shows minimum anomalies, nearly $-70 \mathrm{mGals}$, and steep gradients. The central mountainous area around Omi and Sakai shows high Bouguer anomalies, -20 to $-5 \mathrm{mGals}$, and may correspond to the structure of wholly distributed uplifting basement rocks beneath the Central Uplift Zone.

The feature is clearer on the residual map with the removal of the upward continuation of the filtering processing. The residual map is shown in Fig. 3. The area colored with red/blue is the area of positive/negative values. The residual anomalies related to a structure shallower than several $\mathrm{km}$ are extracted by a low-cut filter designed with 


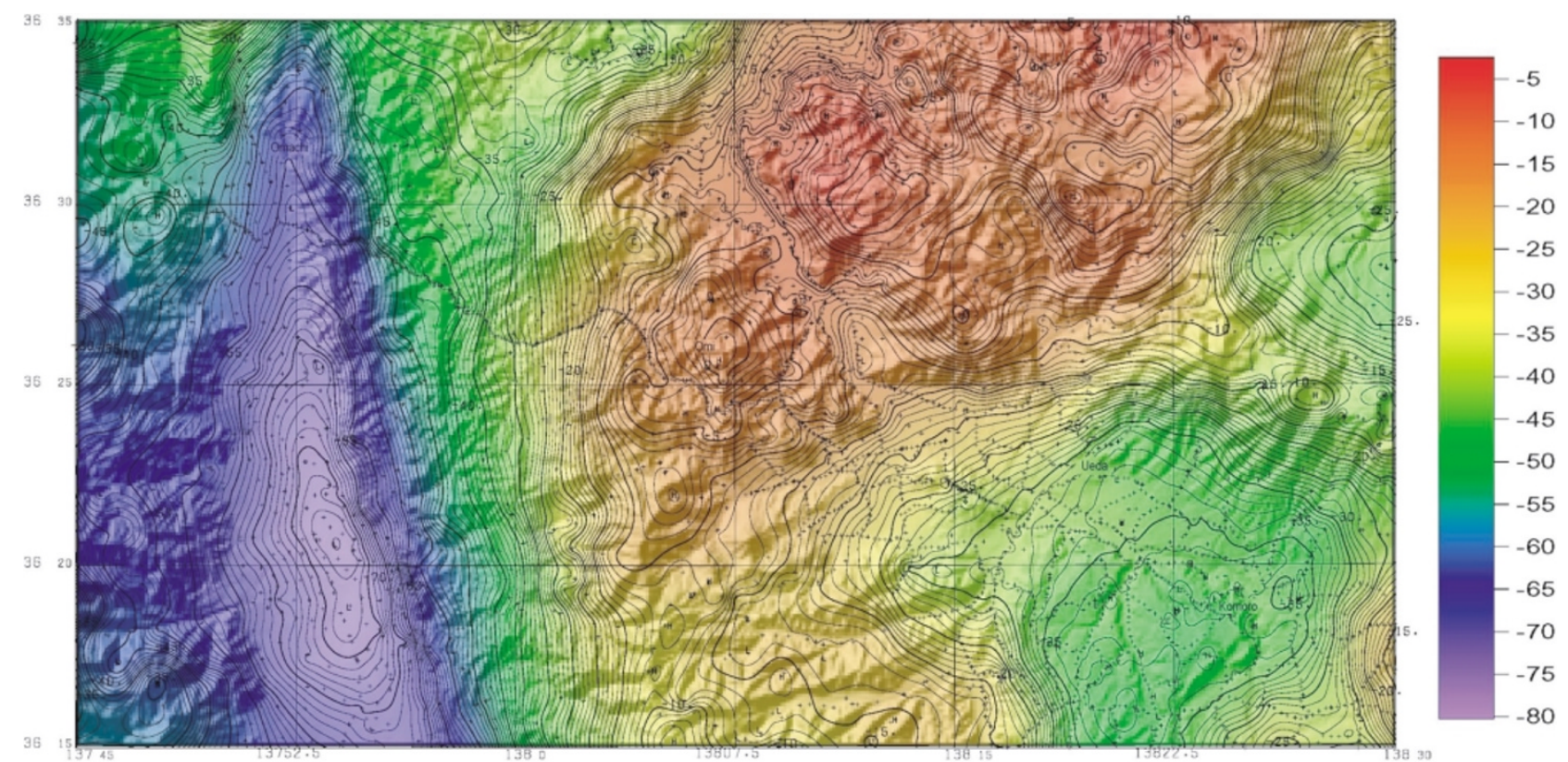

Fig. 2. Regional Bouguer anomalies with an assumed density of $2,670 \mathrm{~kg} / \mathrm{m}^{3}\left(2.67 \mathrm{~g} / \mathrm{cm}^{3}\right)$. The contour intervals are $10 \mu \mathrm{N} / \mathrm{kg}(1 \mathrm{mGal})$. Gravity stations are shown with crosses. Relief is topographical and made from the $50 \mathrm{~m}$ digital elevation model of the Geographical Survey Institute.



Fig. 3. Gravity residual inferred from a shallow structure. Regional trends are removed with the $2 \mathrm{~km}$ upward-continuation. Line A-B indicates the location of the two-dimensional gravity analysis. The result of crustal modeling is shown in Figs. 4 and 5. Relief is topography and made from a 50 $\mathrm{m}$ digital elevation model of the Geographical Survey Institute. ISTL and ONF denote the Itoigawa-Shizuoka Tectonic Line and the Otari-Nakayama Fault, respectively. Geological setting between ISTL and ONF is called "the Omine belt".

upward-continuation filters. Strictly speaking, the regional trends are calculated from an upward continuation of $2 \mathrm{~km}$. Only one conspicuous point is commented on here, that is, a extremely low anomaly belt with a $5 \mathrm{~km}$ width, the axis of $137^{\circ} 54^{\prime}$ east longitude, extends from north to south, which corresponds to the graben structure generated by the activity of the Itoigawa-Shizuoka Tectonic Line. The minimum residuals are observed about $2 \mathrm{~km}$ east of Omachi City, $36^{\circ} 28^{\prime}$ north latitude and $137^{\circ} 54^{\prime}$ east longitude, which is locally $200 \mathrm{~m}$ higher than other surrounding places i.e. Omachi City, about $750 \mathrm{~m}$ altitude. It is uncommon that the higher site, or hill, has lower residuals than the basin floor. The estimated models are followed as the density of the hill is lower than the basin floor deposit or that the low-density sediments are lying beneath the hill, which is a fold structure. The geologic zone between ISTL and the Otari-Nakayama fault is called the Omine belt (Geological Survey of Japan, 1974) and consists of Pliocene unconsol- 

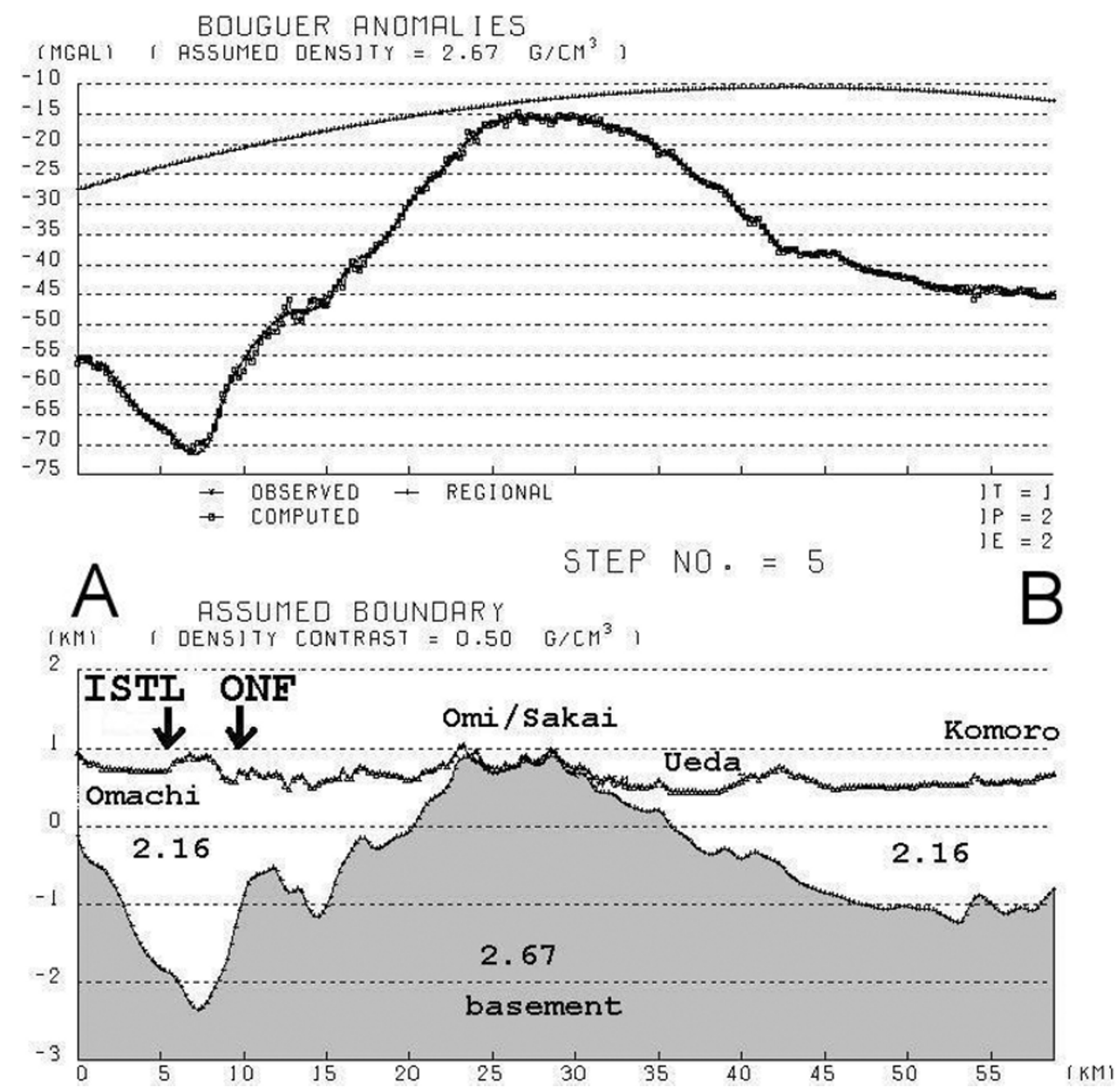

Fig. 4. The result of automatic two-dimensional two-layer analysis. Bouguer gravity profiles (top) and the crustal cross-section (bottom) along the line A-B are inferred. Density contrast is $500 \mathrm{~kg} / \mathrm{m}^{3}\left(0.5 \mathrm{~g} / \mathrm{cm}^{3}\right)$. The location of the profile A-B is shown in Fig. 3. Exageration of the vertical direction horizontal is 5 times. ISTL and ONF denote the Itoigawa-Shizuoka Tectonic Line and the Otari-Nakayama Fault, respectively.

idated sand and gravel, which are equivalent in lithology to present-day basin-fill sediments underlying the Omachi basin, so it is estimated that the density of the Omine belt is not so high, less than $2,200 \mathrm{~kg} / \mathrm{m}^{3}$ (refer to Fig. 1). Thus, a remarkable gravity low around the Omachi area is located not at ISTL but at the Otari-Nakayama fault to the east. The Otari-Nakayama fault merges southward to ISTL around $36^{\circ} 20^{\prime}$ north latitude.

\section{Two and Three-Dimensional Analysis}

The methods of two- and three-dimensional analysis were according to Komazawa (1995). A two-dimensional analysis was carried out at one profile (Fig. 3), which corresponded to the profiles of the seismic reflection and refraction method. In the first step, an automatic analysis of a simple model of homogeneous two layers, without the information of the geological setting, was carried out. Two layers correspond to the basement bedrock and the sedimentary layer, and the density contrast was assumed to be 500 $\mathrm{kg} / \mathrm{m}^{3}$. The result is shown in Fig. 4. The thickness of the sedimentary layer reaches $2 \mathrm{~km}$ at the western area, around Omachi City, and is of low anomaly. Briefly, this result is similar to the result of the seismic refraction survey car- ried out in 2002 (Imai et al., 2004), excepting that the density structure is shallow, about $0.5 \mathrm{~km}$ around Omachi and about $1 \mathrm{~km}$ around Komoro, compared with the P-wave velocity, $4.5 \mathrm{~km} / \mathrm{s}$, structure. But the undulations of the basement might also result from near-surface density changes associated with shallow geological bodies such as the lowdensity sediments. In the next step, where it is difficult to make a multi-layer model, i.e. fold structure, forward modeling was carried out using density sediments. Referring to the surface layer density estimation, the result of the seismic survey (Ikami et al., 1986; Imai et al., 2004; Sato et al., 2004) and the geological setting (Geological Survey of Japan, 1989), low gravity residuals in the eastern area of Omachi City might be derived from the fold structure. Therefore, multi-layer modeling was conducted by estimating the fold structure in the eastern area of the ISTL, and the result is shown in Fig. 5. The most characteristic point is that the low-density sediment (2.0) around Omachi is estimated to exist beneath the hill of a little denser density (2.2). Okubo et al. (2000) had also presented a two-dimensional density structure along a profile of the vibroseis reflection survey, which is almost the same, about $5 \mathrm{~km}$ north of this study profile. Comparing the two models, the fold struc- 

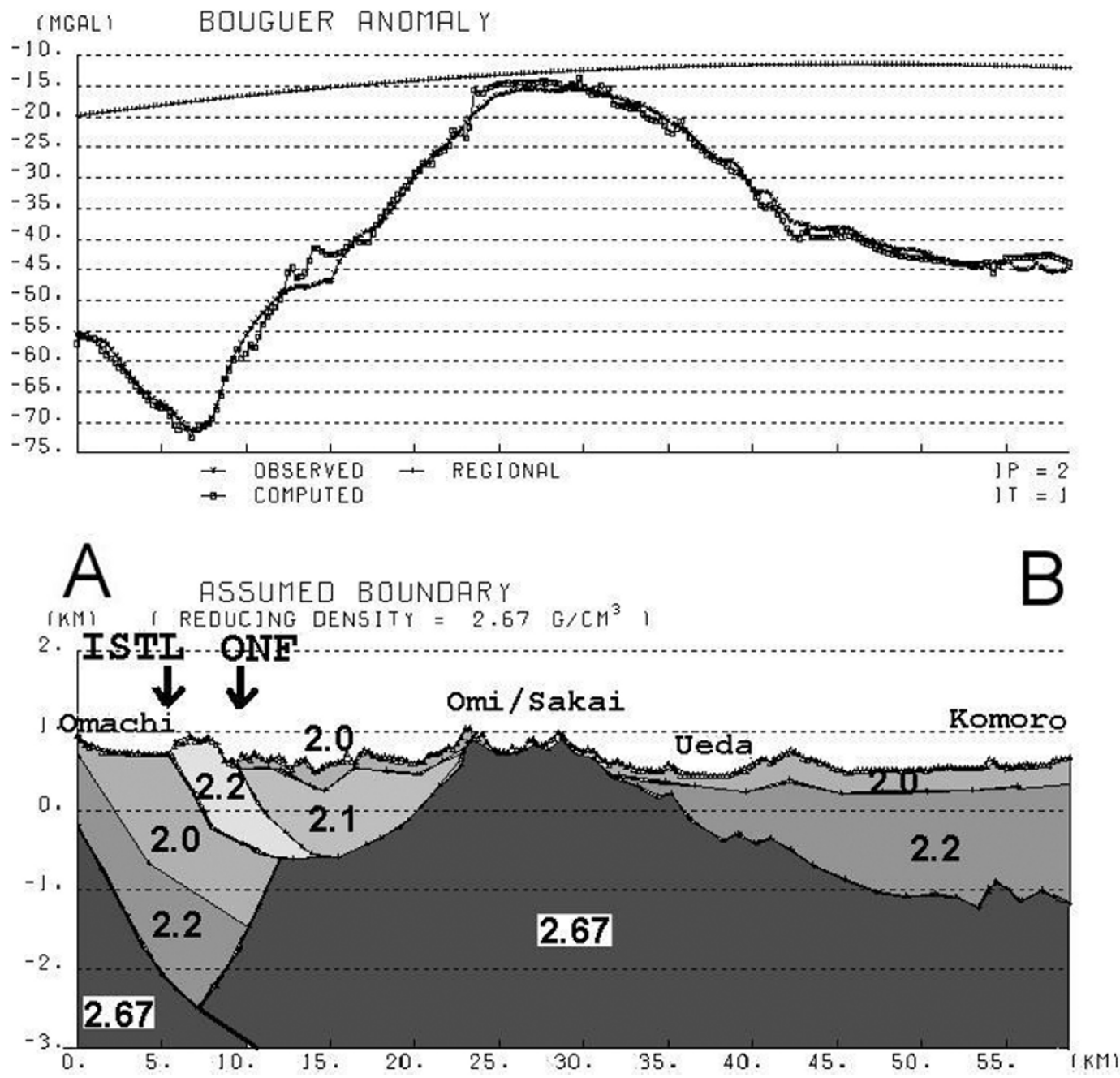

Fig. 5. The result of two-dimensional multi-layer modeling. Bouguer gravity profiles (top) and crustal cross-section (bottom) along the line A-B are inferred. The values of the model denote density in $1,000 \mathrm{~kg} / \mathrm{m}^{3}\left(\mathrm{~g} / \mathrm{cm}^{3}\right)$. The location of the profile A-B is shown in Fig. 3. Exageration of the vertical direction horizontal is 5 times.

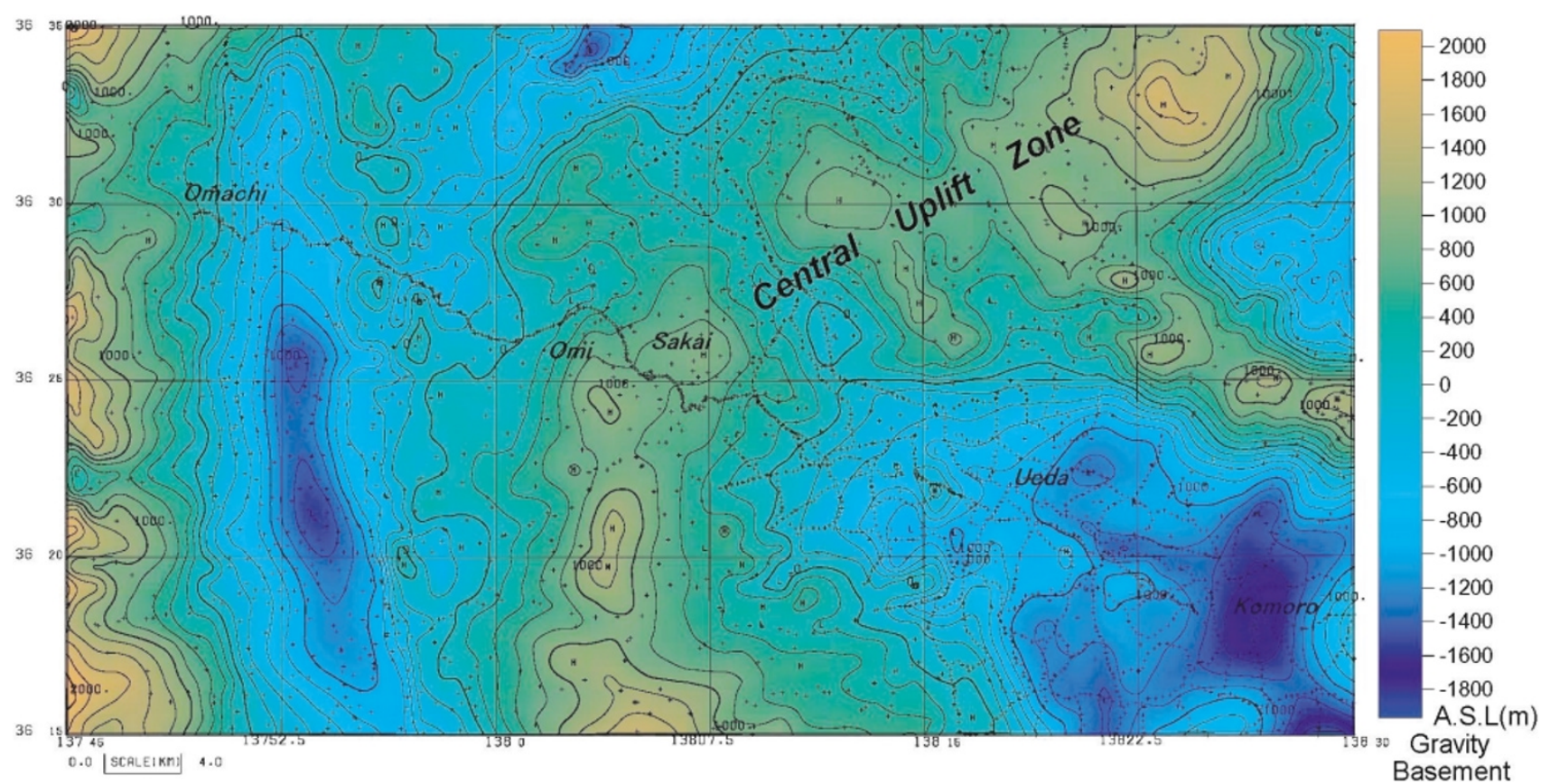

Fig. 6. Gravity basement in meters above sealevel with a density contrast of $500 \mathrm{~kg} / \mathrm{m}^{3}\left(0.5 \mathrm{~g} / \mathrm{cm}^{3}\right)$. The contour interval is $200 \mathrm{~m}$. Gravity stations are shown by crosses. 
ture is estimated by both models, but the author's model is different from that of Okubo et al. in that the high density basement is rising to near surface on the eastern side and the low density basin sediment is folding deeply beneath the Omine belt. The fold structure is thought to extend north and south beneath the ISTL, because the configuration of the Bouguer anomalies shows an almost two-dimensional pattern along the ISTL.

The three-dimensional gravity basement (Fig. 6) was derived from the three-dimensional analysis. The basement depth was controlled at about zero, $0 \mathrm{~m}$, at the mountainous area and the density contrast was assumed to be $500 \mathrm{~kg} / \mathrm{m}^{3}$. It also shows that the depth is more than $2 \mathrm{~km}$ at the central region of low anomaly in the Matsumoto basin and the gradient of the basements structure is steep at the eastern edge of the ISTL, or the Otari-Nakayama Fault. Other deep basements more than $2 \mathrm{~km}$, or lower than $-1,500 \mathrm{~m}$ above sea level, are found around Ueda City and Komoro City, which shows the basin topographically. The basin is considered to be a field with thick low-density sediments. The gravity-basement in the Central Uplift Zone is very shallow, or higher than $1,000 \mathrm{~m}$ above sea level, and it matches the result of seismic surveys (Sato et al., 2004). Another shallow gravity basement is found in the western part of this study area, Hida Mountains, and it is reasonable to assume that the high-density Pre-Neogene rocks outcrop there.

\section{Conclusion}

A low gravity anomaly extending north and south around Omachi City or the Matsumoto basin, with a steep gradient on the eastern part, corresponds to the thick sediment and to the ISTL. The result of the surface layer density analysis and two-dimensional multi-layer forward modeling explains that steep, gradients are inferred from the fold structure where the low-density sediment layer folds beneath the smaller high-density, older sediment making the hills. A map of the gravity basement, derived from gravity data, shows that the basement depth is often more than 2 $\mathrm{km}$ in the Matsumoto basin extending north and south and in the Ueda-Komoro basin region. The basement around Omi and Sakai, the Central Uplift Zone, is very shallow or almost reaches the ground, and it explains the geological setting, i.e. Middle Miocene sediments, Neogene intrusive rock, and Pliocene andesite.

Acknowledgments. The author thanks two reviewers, Dr. T. Takeda of the National Institute of Advanced Industrial Science and Technology and the anonymous one for valuable comments which were very useful in the revision article. This study was carried out as part of the research project "Slip and Flow Process in and below the Seismogenic Region", which was supported by the Ministry of Education, Culture, Sports, Science and Technology, Japan.

\section{References}

Geological Survey of Japan, 1:500,000 Geological Map / KANAZAWA (2nd ed.), 1974

Geological Survey of Japan, 1:200,000 Geological Map / TAKAYAMA, 1989.

Geological Survey of Japan, 1:200,000 Geological Map / NAGANO, 1998. Geological Survey of Japan, Gravity CD-ROM of Japan, DGM P-2, 2000. Ikami, A., T. Yoshii, S. Kubota, Y. Sasaki, A. Hasemi, T. Moriya, H. Miyamachi, R. S. Matsu'ura, and K. Wada, A seismic-refraction in and around Nagano Prefecture, central Japan, J. Phys. Earth, 34, 457-474, 1986.

Imai, T., T. Iwasaki, T. Takeda, T. Kawanaka, and H. Sato, Detailed upper crustal structure across the Itoigawa-Shizuoka Tectonic Line from the 2002 Seismic Expedition, Proceedings of the Second International Symposium on Slip and Flow Processes in and below the Seismogenic Region, 2-5, (2) 1-6, 2004.

Komazawa, M. A gravimetric terrain correction method by assuming annular prism model, J. Geod. Soc. Japan, 34, 11-23, 1988 (in Japanese with English abstract).

Komazawa, M., Gravimetric analysis of Aso Volcano and its interpretation, J. Geod. Soc. Japan, 41, 17-45, 1995.

Okubo, S., Y. Ikeda, T. Kumamoto, G. Seta, N. Matuta, H. Chiba, and Y. Arai, 2-D and 3-D subsurface density structure in the northern part of the Itoigawa-Shizuoka Tectonic Line derived by gravity surveying, $J$. Geod. Soc. Japan, 46, 177-186, 2000.

Sato, H., T. Iwasaki, S. Kawasaki, Y. Ikeda, N. Matsuta, T. Takeda, N. Hirata, and T. Kawanaka, Formation and shortening deformation of a back-arc rift basin revealed by deep seismic profiling, central Japan, Tectonophysics, 388, 47-58, 2004.

Woollad, G. P., The new gravity system-changes in international gravity base values and anomaly values, Geophysics, 44, 1352-1366, 1979.

Yano, T., Late Cenozoic geohistory in the northern Fossa Magna Region, Central Japan, J. Sci. Hiroshima Univ., Ser. C,9, 81-132, 1989.

M. Komazawa (e-mail: komazawa-m@aist.go.jp) 